\title{
Pengaruh penambahan ekstrak minyak tenggiri pada umpan bubu terhadap hasil tangkapan ranjungan di perairan Malalayang, Kota Manado
}

\author{
The effect of mackerel oil extract added to trap baits on the catch of swimming crab in \\ Malalayang waters, Manado City
}

\author{
THOMSON M. WATEM*, HENRY J. KUMAJAS dan FANNY SilOOY \\ Program Studi Pemanfaatan Sumberdaya Perikanan, Fakultas Perikanan dan Ilmu Kelautan, \\ Universitas Sam Ratulangi, Manado 95115
}

\begin{abstract}
Swimming crab (Portunus pelagicus) is one of the economically important marine product commodities resulting from coastal waters Indonesia. Swimming crab in coastal waters of North Sulawesi usually caught accidentally with bottom gillnet. There has been a special fishing gear for crab traps, but not known by local fishermen. Addition of mackerel oil extract on baits could increase the fishing power of swimming crab traps but this kind of scientific information, particularly on swimming crab, not widely available yet. This research aims to study the effect of mackerel oil extract on traps bait to catch swimming crab; and to identify the types of biota captured. This research was conducted in coastal waters of Malalayang Satu, Malalayang District, Manado City; in December 2014 to January 2015; which is based on experimental methods. Six units of trap were operated seven nights; where tree units of them used scad mackerel bait that injected by mackerel oil extract, and tree other units just used scad mackerel bait without mackerel oil extract; and the capture data were analyzed by $\mathrm{t}$ test. The catch was 58 swimming crab in total; 42 fish was caught by scad mackerel bait with mackerel oil extract, and 16 swimming crab was caught by bait without mackerel oil extract. Analysis of $t$ test showed that the use of mackerel oil extracts in bait traps, giving different swimming crab catches compared with bait without mackerel oil extracts.
\end{abstract}

Keywords: swimming crab, trap, mackerel oil, Malalayang Manado

\begin{abstract}
ABSTRAK
Ranjungan (Portunus pelagicus) merupakan salah satu komoditi hasil laut ekonomis penting yang dihasilkan dari perairan pantai Indonesia. Rajungan di perairan pantai Sulawesi Utara biasanya tertangkap tanpa sengaja dengan jaring insang dasar. Sebenarnya telah ada alat tangkap bubu khusus untuk rajungan, tetapi belum dikenal oleh nelayan lokal. Pemberian ekstrak berupa minyak tenggiri pada umpan diduga dapat meningkatkan kemampuan tangkap dari bubu ranjungan; namun informasi ilmiah seperti ini, khususnya pada ranjungan, belum banyak tersedia. Penelitian ini bertujuan untuk mempelajari pengaruh ekstrak minyak tenggiri pada umpan bubu terhadap hasil tangkapan ranjungan; dan mengidentifikasi jenis-jenis biota yang tertangkap. Penelitian ini dilakukan di perairan pantai Kelurahan Malalayang Satu, Kecamatan Malalayang, Kota Manado; pada bulan Desember 2014 sampai bulan Januari 2015; yang didasarkan pada metode experimental fishing. Enam unit bubu dioperasikan tujuh malam; di mana tiga unit menggunakan umpan ikan layang yang disuntikkan ekstrak minyak tenggiri, dan tiga unit lainnya hanya menggunakan umpan ikan layang tanpa ekstrak; dan data dinalisis dengan uji t. Tangkapan total berjumlah 58 ekor; 42 ekor tertangkap dengan umpan layang yang diberi ekstrak minyak tenggiri, dan 16 ekor tertangkap dengan umpan tanpa ekstrak minyak tenggiri. Hasil analisis uji t menunjukkan bahwa penggunaan ekstrak minyak tenggiri pada umpan bubu memberikan hasil tangkapan ranjungan yang lebih banyak dibandingkan dengan umpan tanpa ekstrak minyak tenggiri.
\end{abstract}

Kata-kata kunci: rajungan, bubu, minyak tenggiri, Malalayang Manado.

\footnotetext{
*Penulis untuk penyuratan; email: thompson@yahoo.com
} 


\section{PENDAHULUAN}

Rajungan (Portunus pelagicus) merupakan salah satu komoditi hasil laut ekonomis penting yang dihasilkan dari perairan pantai Indonesia. Permintaan pasar terhadap komoditas ranjungan terus meningkat. Di beberapa negara seperti Amerika Serikat, Jepang, Korea Selatan, Taiwan dan Australia, komoditas ranjungan tetap menjadi konsumsi penting sehingga merupakan pangsa pasar ekspor yang strategis dengan nilai jual yang tinggi. Komoditas ranjungan dari dalam negeri hasil penangkapan ikan mendominasi produk untuk ekspor (Zarochman, 2006). Selanjutnya Asmara (2004) menyebutkan bahwa rajungan merupakan komoditi perikanan yang memiliki nilai jual tinggi karena memiliki rasa yang lezat dan kandungan gizi yang tinggi.

Produk rajungan nasional diperoleh dengan cara budidaya dan penangkapan. Penangkapan rajungan langsung dari alam dilakukan dengan menggunakan berbagai jenis perangkap dan salah satunya bubu (Rakhmadevi, 2004). Bubu merupakan alat penangkapan ikan yang bersifat pasif, yakni memudakan ikan untuk masuk namun sulit untuk meloloskan diri (Mawardi, 2001).

Miler (1990) menyatakan bahwa keberhasilan penangkapan menggunakan bubu dipengaruhi oleh beberapa faktor seperti konstruksi bubu, lama perendaman (soaking time) dan umpan. Umpan merupakan salah satu faktor penting dalam menunjang keberhasilan suatu oprasi penangkapan ikan, khususnya untuk alat tangkap pasif seperti bubu dan pancing (Subani dan Barus 1989). Alat tangkap bubu biasanya menggunakan umpan alami berupa ikan, karena mudah didapat dan masih memiliki kesegaran yang baik (Ramdani, 2007).

Di perairan pantai Sulawesi Utara, rajungan biasanya tertangkap tanpa sengaja (by catch) dengan jaring insang dasar. Sebenarnya telah ada alat tangkap bubu khusus untuk rajungan, tetapi belum dikenal oleh nelayan lokal. Pemberian ekstrak berupa minyak tenggiri pada umpan, diduga dapat meningkatkan kemampuan tangkap dari bubu ranjungan; namun informasi ilmiah hal ini belum banyak tersedia. Penelitian ini bertujuan untuk mempelajari pengaruh ekstrak minyak tenggiri pada umpan bubu terhadap hasil tangkapan ranjungan; dan untuk mengidentifikasi jenis-jenis biota yang tertangkap berdasarkan perlakuan.

\section{METODE PENELITIAN}

Penelitian ini dilakukan di perairan pantai Kelurahan Malalayang Satu, Kecamatan Malalayang, Kota Manado. Waktu pelaksanaannya dari bulan Desember 2014 sampai bulan Januari 2015.

Penelitian ini dikerjakan dengan mengikuti metode eksperimental, yaitu suatu rancangan percobaan yang diujicobakan untuk memperoleh informasi tentang persoalan yang sedang diteliti. Dengan metode ini dapat diperoleh informasi yang diperlukan dalam melakukan penelitian tentang persoalan yang akan dibahas sehingga akan dihasilkan suatu kesimpulan sesuai dengan tujuan penelitian (Sudjana, 1994).

Bahan dan alat yang digunakan dalam penelitian terdiri dari: 6 unit bubu ranjungan, umpan ikan layang (Decapterus sp.), ekstrak minyak tenggiri, perahu tipe pelang, bahan bakar bensin, motor katinting; alat tulis menulis, peralatan suntik, timbangan, meteran dan kamera digital.

Pengumpulan data dilakukan dengan mengoperasikan 6 unit bubu rajungan di perairan pantai Kelurahan Malalayang Satu selama 7 trip. Tiga unit bubu menggunakan umpan ikan layang yang diberi ekstrak minyak tenggiri, sedangkan tiga unit bubu lainnya hanya menggunakan umpan ikan layang tanpa ekstrak minyak tenggiri. Kedalaman perairan daerah operasi penangkapan sekitar 5-7 $\mathrm{m}$. Penurunan alat tangkap bubu dilakukan pada sore hari sekitar jam 17.00, kemudian diangkat pada keesokan harinya sekitar jam 06.00 pagi. Hasil tangkapan bubu pada setiap pengamatan diidentifikasi, diukur dan dicatat berdasarkan pada masing-masing perlakuan.

Untuk memenuhi persyaratan analisis dalam menarik kesimpulan, maka dirumuskan hipotesis sebagai berikut:

$\mathrm{H}_{0}=$ Penggunaan ekstrak minyak tenggiri pada umpan bubu tidak berbeda nyata terhadap hasil tangkapan ranjungan;

$\mathrm{H}_{1}=$ Penggunaan ekstrak minyak tenggiri pada umpan bubu berbeda nyata terhadap hasil tangkapan ranjungan;

di mana, $\mathrm{H}_{0}$ diterima $\left(\mathrm{H}_{1}\right.$ ditolak $)$ apabila $\mathrm{t}_{\text {hitung }}<\mathrm{t}$ tabel, $\mathrm{H}_{0}$ ditolak $\left(\mathrm{H}_{1}\right.$ diterima) apabila $\mathrm{t}$ hitung $\geq \mathrm{t}$ tabel. Selanjutnya $t$ hitung dikerjakan menggunakan analisis perbandingan nilai tengah contoh pengamatan berpasangan (Steel and Torrie, 1989) dengan rumusan:

$$
t=\frac{\bar{X}-\bar{Y}}{S_{\bar{D}}}
$$




$$
\begin{aligned}
& S_{\bar{D}}=\frac{\sum D^{2}-\left(\sum D\right)^{2} / n}{n-1} \\
& t=\frac{\bar{X}-\bar{Y}}{\sqrt{\frac{\sum D^{2}-\left(\sum D\right)^{2} / n}{n-1}}}
\end{aligned}
$$

di mana $\bar{X}$ adalah rata-rata tangkapan bubu dengan umpan berekstrak, $\bar{Y}$ adalah rata-rata tangkapan bubu dengan umpan tanpa ekstrak, dan $D=X-Y$.

\section{HASIL DAN PEMBAHASAN}

\section{Hasil tangkapan}

Hasil tangkapan bubu selama penelitian berjumlah 58 ekor ranjungan, sebanyak 42 ekor tertangkap dengan umpan berekstrak minyak tenggiri dan 16 ekor tertangkap dengan umpan tanpa ekstrak tenggiri. Sebaran hasil tangkapan ranjungan pada setiap trip dan ulangan disajikan dalam Tabel 1 dan Gbr. 1.

\section{Hasil analisis}

Untuk kepentingan analisis uji t, maka data dalam Tabel 1 disederhanakan dan diolah lebih lanjut menjadi seperti Tabel 2.

Tabel 1. Sebaran hasil tangkapan ranjungan (ekor).

\begin{tabular}{ccccccccc}
\hline \multirow{2}{*}{$\begin{array}{c}\text { Trip } \\
\text { operasi }\end{array}$} & \multicolumn{8}{c}{ Umpan berekstrak } \\
\cline { 2 - 9 } & 1 & 2 & 3 & T & 1 & 2 & 3 & T \\
\hline 1 & 2 & 2 & 3 & 7 & 1 & - & 1 & 2 \\
2 & 2 & 2 & 3 & 7 & - & 1 & 2 & 3 \\
3 & 1 & 2 & 4 & 7 & - & - & 1 & 1 \\
4 & 2 & 1 & 2 & 5 & 1 & 1 & 1 & 3 \\
5 & 1 & 2 & 3 & 6 & 1 & 1 & - & 2 \\
6 & 1 & 1 & 3 & 5 & 1 & 1 & 1 & 3 \\
7 & 2 & 1 & 2 & 5 & 1 & 1 & 0 & 2 \\
\hline Jumlah & 11 & 11 & 20 & 42 & 5 & 5 & 6 & 16 \\
\hline
\end{tabular}

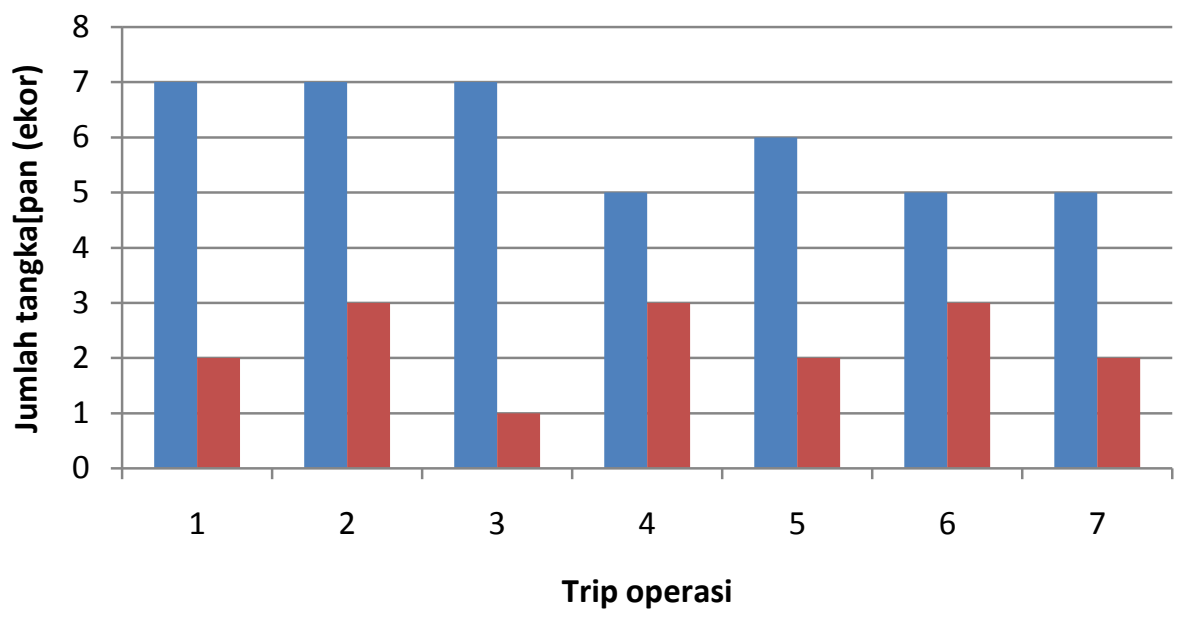

- Umpan berekstrak Umpan tanpa ekstrak

Gambar 1. Sebaran hasil tangkapan ranjungan menurut trip operasi 
T.M. Watem dkk.

Tabel 2. Analisis perbandingan nilai tengah contoh pengamatanterhadap hasil tangkapanranjungan dengan bubu

\begin{tabular}{ccccc}
\hline Trip & Bubu Berekstrak $(\mathrm{X})$ & Bubu Tanpa Ekstrak $(\mathrm{Y})$ & $\mathrm{D}(\mathrm{X}-\mathrm{Y})$ & $\mathrm{D}^{2}$ \\
\hline 1 & 7 & 2 & 5 & 25 \\
2 & 7 & 3 & 4 & 16 \\
3 & 7 & 1 & 6 & 36 \\
4 & 5 & 3 & 2 & 4 \\
5 & 6 & 2 & 4 & 16 \\
6 & 5 & 3 & 2 & 4 \\
7 & 5 & 2 & 3 & 9 \\
\hline Total & 42 & 16 & 26 & 110 \\
\hline Rataan & 6,00 & 2,29 & & \\
\hline
\end{tabular}

$\bar{X}=6,00 ; \bar{Y}=2,29 ;(\Sigma \mathrm{D})^{2}=26^{2}=676 ; \Sigma \mathrm{D}^{2}=$ $110 ; \bar{X}-\bar{Y}=3,71 ;$ taraf nyata $(\alpha)=5 \%(0,05)$; nilai $\mathrm{t}$ tabel dengan derajat bebas $(\mathrm{db})=\mathrm{n}-1=5$ adalah $\mathrm{t}_{0,05 ; 6}=2,447$; dan $\mathrm{t}$ hitung adalah

$$
t=\frac{6,00-2,29}{\sqrt{\frac{110-676 / 7}{7-1}}}=2,479
$$

Hasil analisis menunjukkan bahwa t hitung = $2,479>\mathrm{t} \mathrm{tabel}_{0,05 ; 6}=2,447$; sehingga menolak $\mathrm{H}_{0}$ dan menerima $\mathrm{H}_{1}$, di mana hal ini ini menjelaskan bahwa penggunaan ekstrak minyak tenggiri pada umpan bubu memberikan hasil tangkapan ranjungan yang berbeda dibandingkan dengan umpan tanpa ekstrak minyak tenggiri.

\section{Pembahasan}

Ranjungan cenderung tertangkap dengan umpan yang menggunakan ekstrak minyak tenggiri, karena dilihat tingkah laku dari ranjungan pada saat merespon bau umpan cenderung mendekati kemudian memakannya. Diketahui bahwa umpan ekstrak yang digunakan pada penelitian ini lebih banyak memikat ranjungan untuk masuk ke dalam bubu, dibandingkan dengan umpan tanpa ektrak. Hal tersebut dikarenakan umpan ekstrak memiliki aroma yang lebih tajam dibandingkan dengan jenis umpan tanpa ekstrak. Umpan ekstrak yang digunakan mengeluarkan bau melalui celah mata jaring dari badan bubu dan terbawa oleh aliran air. Reaksi penciuman rajungan disebabkan karena adanya bau yang larut dalam air. Hal ini dikarenakan kebiasaan makan ranjungan adalah ikan atau makanan yang baunya hanyut merangsang penciuman ranjungan sehingga dengan ekstrak minyak tenggiri rajungan lebih tertarik untuk memakan umpan tersebut dibandingkan dengan umpan tanpa ektrak minyak tenggiri.

Hasil tangkapan rajungan pada umpan yang menggunakan ekstrak minyak tenggiri lebih banyak yaitu 42 ekor atau rata-rata 6 ekor per hari dan pada bubu yang tidak menggunakan umpan ekstrak minyak tenggiri yaitu 16 ekor atau ratarata 3 ekor per hari. Ini berarti ada perbedaan hasil tangkapan pada bubu yang menggunakan umpan ekstrak minyak tenggiri dan yang tidak menggunakan.

\section{KESIMPULAN}

1) Umpan bubu yang diberi ekstrak minyak tenggiri menghasilkan tangkapan ranjungan yang lebih banyak dibandingkan dengan umpan tanpa ekstrak.

2) Hasil tangkapan bubu hanya terdiri dari ranjungan jenis Portunus pelagicus.

\section{DAFTAR PUSTAKA}

Asmara, H. 2004. Analisis beberapa aspek reproduksi kepiting bakau (Scylla serrate) di perairan Segara Anakan, Kabupaten Cilacap, Jawa Tengah. Skipsi. Fakultas perikanan, Institut Pertanian Bogor, Bogor.

Miller. 1990. Effectiveness of crab and lobster trap. Marine Fisheries Research Journal 47:1228-1249.

Mawardi, M.M. 2001. Pengaruh penggunaan jenis umpan terhadap hasil tangkapan ikan karang pada alat Tangkap bubu (trap) di Pulau Pramuka Kepulauan Seribu. Skripsi. Fakultas Perikanan, Institut Pertanian Bogor, Bogor.

Rakhmadevi, C.C. 2004. Waktu perendaman dan periode bulan pengaruhnya terhadap rajungan hasil tangkapan bubu di muara Sungai Radak, Pontianak. Skripsi. Fakultas Perikanan, Institut Pertanian Bogor, Bogor.

Ramdani, D. 2007. Perbandingan hasil tangkapan rajungan pada bubu lipat dengan menggunakan umpan Yang berbeda. Skripsi. Fakultas Perikanan, Institut Pertanian Bogor, Bogor. 
Steel, R.G.D. dan J.H. Torrie. 1989. Principles and Procedures of Statistics. 2nd ed. McGraw Hill International Book Company, London.

Subani,W. dan H.R. Barus. 1989. Alat penangkapan ikan dan udang laut di Indonesia. Jurnal Penelitian Perikanan Laut 50(Edisi Khusus). Balai Penelitian Perikanan Badan Penelitian dan Pengembangan Pertanian Departemen Pertanian, Jakarta.
Sudjana. 1994. Desain dan Analisis Eksperimen. Edisi III. Tarsito, Bandung.

Zarochman, 1996. Klasifikasi Alat Penangkapan Ikan Yang di sesuaikan untuk Perairan Indonesia. Edisi 2. Teknologi Penangkapan Ikan, Balai Pengembangan Penangkapan Ikan, Semarang. 